\title{
An Analysis of Moodle Acceptance for Students in SMPK2 PENABUR Using Unified Theory of Acceptance and Use of Technology Model
}

\author{
D Fernando $^{1^{*}}$ \\ ${ }^{1}$ Faculty of Engineering and Information Technology, Swiss German University, \\ Tangerang 15143, Indonesia \\ *Corresponding author: danif98@gmail.com
}

\begin{abstract}
The synergy of combining globalization with new technology has had dramatic learning impacts. Teachers and Students need to work together to successfully implement Moodle as one of learning technologies. Author needs to determine factors that are important to use Moodle. UTAUT was created based on the conceptual and empirical similarities across TAM, TAM2 and TAM3 models. UTAUT model attempts to explain how individual differences influence technology use. Structural Equation Modelling (SEM) is then used to assess the reliability and validity of the model measures. Exploratory Research is conducted in order to determine the nature of the problem and is not intended to provide conclusive evidence. With Uncontrolled Quota Sampling method, respondents filled Likert-scale questions. Analysis of a Moment Structures (AMOS) is used analyse the data using SEM. All hypotheses is verified through different set of experiments. UTAUT is acceptable of analysing respondents' acceptance in using Moodle. Each construct uniquely affects the output, therefore different strategies can be implemented based on respondents' characteristics. Performance Expectancy is important for Students.
\end{abstract}

\section{Introduction}

Schools tried to adapt learning technologies which combine text, audio, video, animation and simulation, deliver them through the internet, and students can learn virtually from anywhere and anytime by using their computer and internet connection.

Teachers are responsible for displaying learning resources in more attractive ways, making the learning process more interesting and enjoyable because some students are more receptive to some kind of information than the others (Franzoni, Ana Lidia, and Said Assar, 2009).

Moodle is one of learning technology available, is an open source web-based application. Moodle can be accessed anywhere and anytime, provide features such as storing documents, managing quizzes and information resources. Moodle is also an alternative of providing materials and access to learning activities where face-to-face or classroom activities are limited. Teachers can upload various material digitally to Moodle, then students access those materials depends on their need and learning speed.

Venkatesh (Venkatesh et al, 2003) developed the Unified Theory of Acceptance and Use of Technology (UTAUT) model as a consolidation of previous TAM model. UTAUT serves as a useful tool for decision makers to determine key success factors for new technology implementation and helps them understand factors of acceptance in order to proactively design training materials and marketing, targeted at group of users that may be more difficult to embrace and use new technology. This paper focuses on determining factors that are significant to get more students to use Moodle using Unified Theory of Acceptance and Use of Technology model.

\section{Materials and Methods}

Currently usage statistics shows that Moodle was accessed by 100 out of 140 students daily. SMPK2 is planning to have Moodle accessed by 140 students next year, therefore we need to examine factors or variables that are significant and important for students to use Moodle, and focuses on Human as root cause of why Moodle is not being used by all students (Figure 1) 


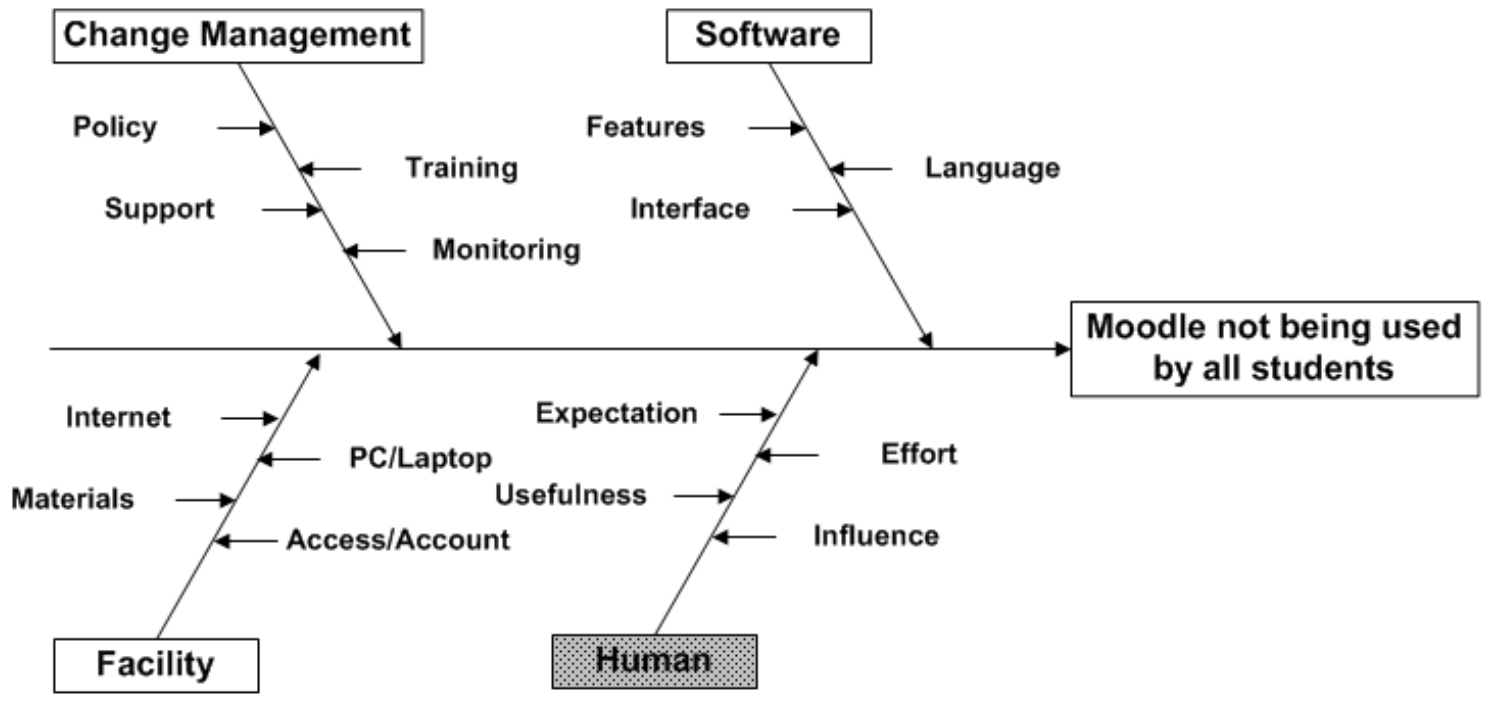

Figure 1 Root Cause Analysis

Hypotheses are visualized in Figure 2, described as follow:

H1: There is a significant relationship between student's attitudes towards using Moodle and its Performance Expectancy.

H2: There is a significant relationship between student's attitudes towards using Moodle and its Effort Expectancy

H3: There is a significant relationship between student's attitudes towards using Moodle and its Social Influence

H4: There is a significant relationship between student's attitudes towards using Moodle and its Computer Self-Efficacy

H5: There is a significant relationship between student's attitudes towards using Moodle and its Perceived Enjoyment

H6: There is a significant relationship between student's attitudes towards using Moodle and its Facilitating Conditions

H7: There is a significant relationship between student's attitudes towards using Moodle and its Behavioural Intention 


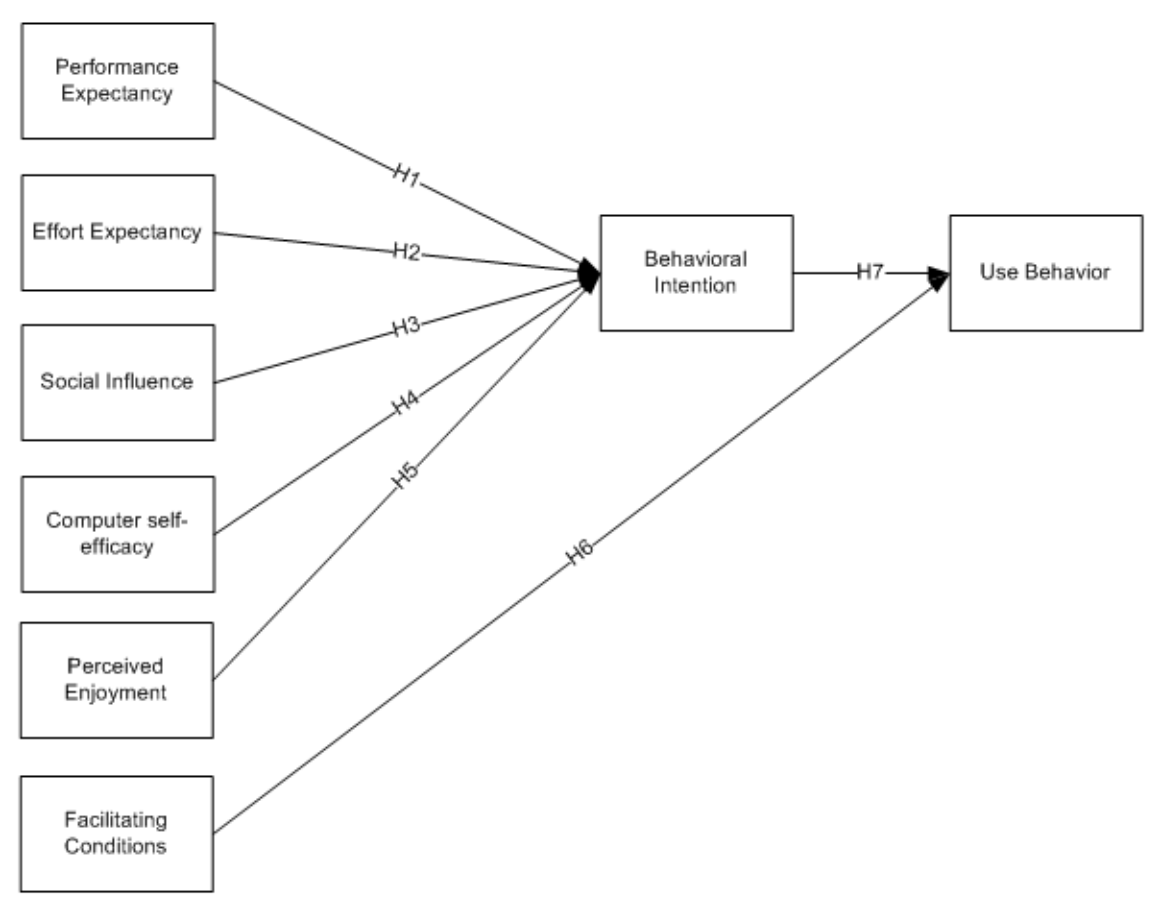

Figure 2 Hypothesis

Unified Theory of Acceptance and Use of Technology (or UTAUT) - suggested in 2003 by Venkatesh, Morris, Davis and Davis, developed based on the theoretical and empiric closeness across existing models. The UTAUT was built with four constructs: Firstly performance expectancy, secondly effort expectancy, thirdly social influence and fourthly facilitating conditions. These constructs are direct determinants or predictors of usage intention and behaviour (Venkatesh et.al. 2003). The predictors are defined as (Venkatesh et al, 2003):

1. Performance expectancy (PE): "is the degree to which an individual believes that using the system will help him or her to attain gains in job performance."

2. Effort expectancy (EE): "is the degree of ease associated with use of the system."

3. Social influence (SI): "is the degree to which an individual perceives that important others believe he or she should use the new system."

4. Facilitating conditions (FC): "is the degree to which an individual believes that an organizational and technical infrastructure exists to support use of the system."

In the UTAUT model, performance expectancy and effort expectancy were adopted to integrate the constructs of perceived usefulness and ease of use. It is crucial to gain its perceived usefulness from the student angle. The results of this research might help schools make better arrangement and campaign and assist teachers in using technology more effectively (Marchewka, Jack T., and Liu Chang, 2007), by considering these perceptions.

\section{Results and Discussion}

We include student respondents in this study. We build the model (Figure 3) as described in research model as well as questions prepared to Students, and Table 1 shows the calculated estimates.

Table 1. Calculated Estimates

\begin{tabular}{cccccccc}
\hline & PEJ & CE & SI & EE & PE & FC & BI \\
\hline BI & $\mathbf{. 1 6 3}$ & $\mathbf{. 3 3 4}$ & $\mathbf{. 1 2 6}$ & $\mathbf{. 0 4 1}$ & $\mathbf{. 3 2 1}$ & .000 & .000 \\
& $\mathbf{( H 5 )}$ & $\mathbf{( H 4 )}$ & $\mathbf{( H 3 )}$ & $\mathbf{( H 2 )}$ & $\mathbf{( H 1 )}$ & & \\
$\begin{array}{c}\text { Use } \\
\text { Behavior }\end{array}$ & .019 & .039 & .015 & .005 & .037 & $\begin{array}{c}\mathbf{. 1 1 1} \\
\mathbf{( H 6 )}\end{array}$ & $\begin{array}{c}\mathbf{. 1 1 6} \\
\text { (H7) }\end{array}$ \\
\hline
\end{tabular}


We summarized those values into Hypothesis Coefficients in table 2 and figure 4.

Table 2. Hypothesis Coefficients

\begin{tabular}{clll}
\hline Hypothesis & \multicolumn{1}{c}{ Effects } & Value & \multicolumn{1}{c}{ Remarks } \\
\hline H1 & PE $\rightarrow$ BI & 0.321 & High effect \\
H2 & EE $\rightarrow$ BI & 0.041 & Low effect \\
H3 & SI $\rightarrow$ BI & 0.126 & Medium Effect \\
H4 & CE $\rightarrow$ BI & 0.334 & High effect \\
H5 & PEJ $\rightarrow$ BI & 0.163 & Medium Effect \\
H6 & FC $\rightarrow$ Use behavior & 0.111 & \\
H7 & BI $\rightarrow$ Use behavior & 0.116 & \\
\hline
\end{tabular}




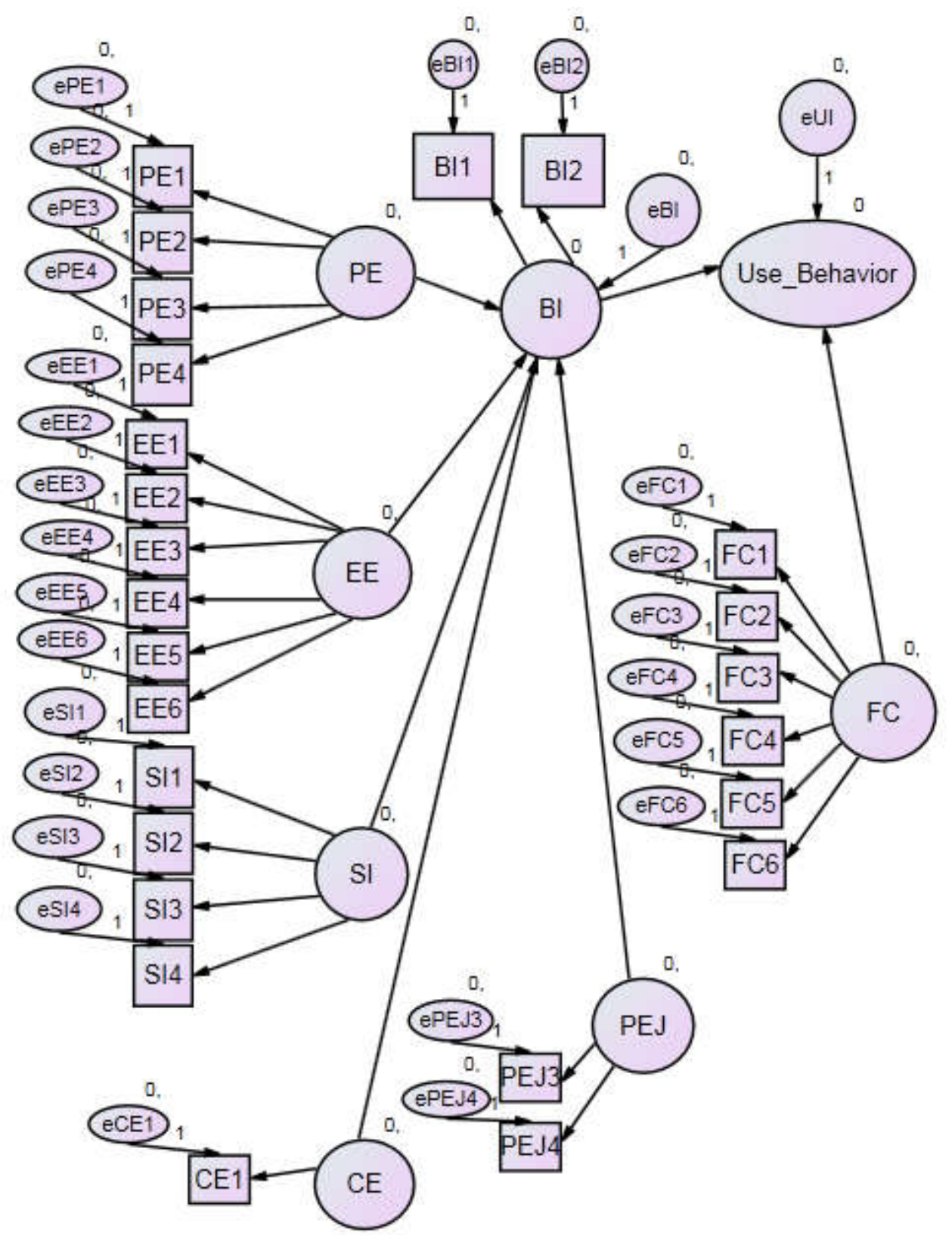

Figure 3 Experiment Model

The greater the hypothesis coefficients, the more necessary the impact it will be. We take Performance Expectancy construct and Computer Self-Efficacy construct as factors significant for respondents. Social Influence and Perceived Enjoyment considered as fair factors, and Effort Expectancy as the least important. We have very slight difference value on Facilitating Conditions and Behavioural Intention. 


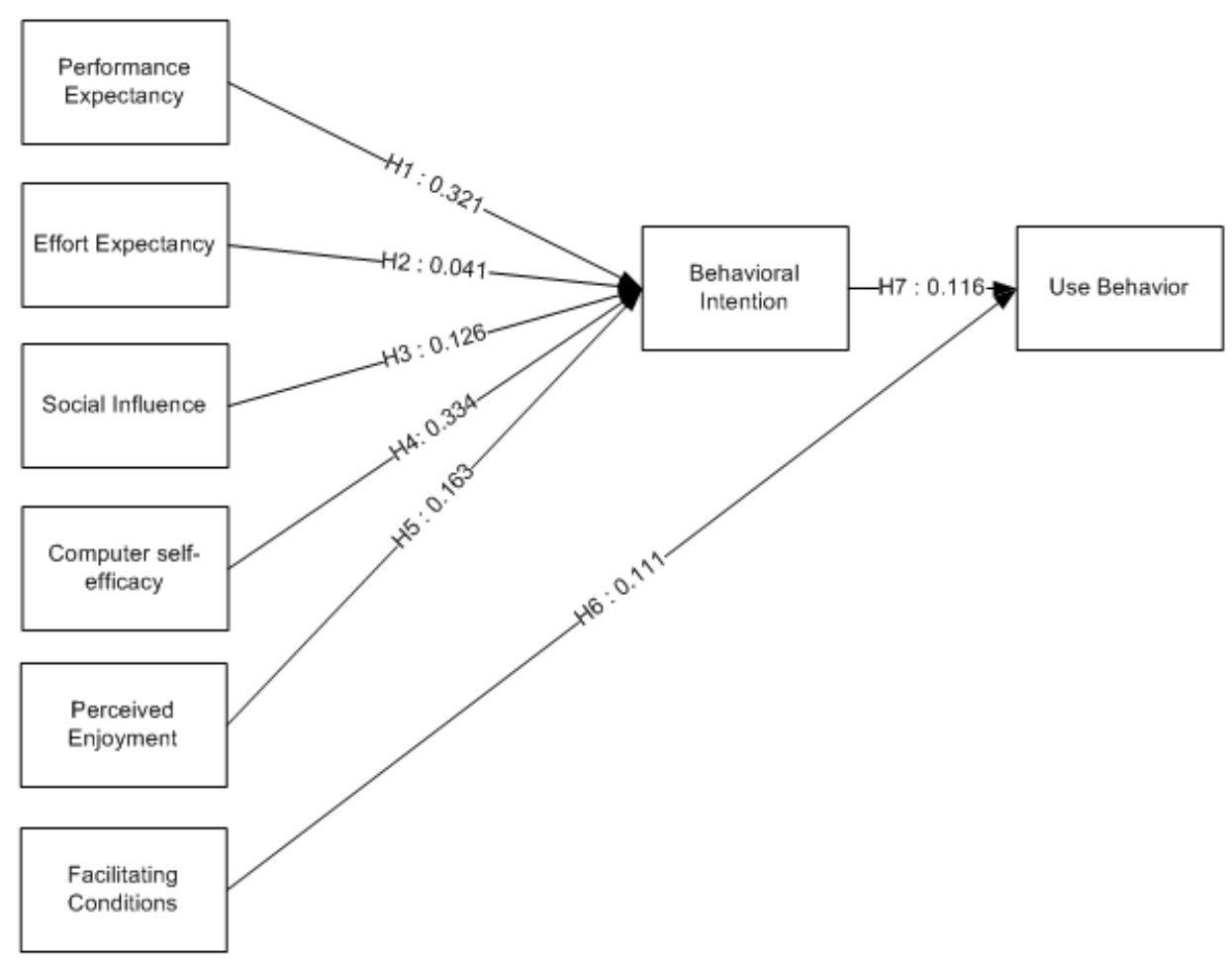

Figure 4 Hypothesis Coefficients

Data from respondents' results are (sorted from the highest) Computer Self-Expectancy, Performance Expectancy, Social Influence and Perceived Enjoyment. Computer Self-Efficacy turns out to be important factor in all the experiment. Therefore the statement in Computer Self-Efficacy question -"I'm an IT-minded Student" became significant. When we observe Performance Expectancy questions, we found that "Moodle useful for understanding topics and achieve higher score" is important as well.

Data from respondents' results "Support from friends, teachers and school" is important. We also discover that "Moodle Easiness" had small effect, meaning Students were convinced in advantage of Moodle even though they might have different level of how to operate Moodle.

"Hardware, Knowledge, Skill, Support Team, Internet and Server Performance" iss an important factor that support the Intention. We conclude that Facilities provided by School, will amplify Intention.

The conclusion is all hypotheses verified.

\section{Conclusion}

It is clear that Unified Theory of Acceptance and Use of Technology is acceptable of analysing Students acceptance in using Moodle. The constructs developed each uniqueness in how it affects the output. These would also can be considered and helpful when creating approaches to ensure more Students interest in using Moodle. Only by implementing different strategies based on student's characteristics, BPK PENABUR Jakarta will succeed in implementing Moodle as a powerful platform for education.

This study is widely opened to improvement. One of the improvements needed is to measure how those factors give us different results on different subjects. This study involved only how respondents accepts Moodle. Parameters at subject level may give us better understanding on how respondents accept specific subject in Moodle environment.

Several recommendations for BPK PENABUR Jakarta in implementing Moodle of other schools as well as SMPK2 new generation as follows:

1. Mind-set comes first. Always state to Students that they are IT-Minded persons and they will be succeeded in using technology when they believe it.

2. Students will accept technology in general, or Moodle in specific, when they know that this technology or Moodle can give them better performances. 


\section{Acknowledgement}

I wish to thank the members of my committee for their support, patience and broaden view. Their gentle but firm direction has been most appreciated. I would like to thank Dr. Ir. Gembong Baskoro, M.Sc. (Advisor) and Dr. Maulahikmah Galinium, S.Kom, M.Sc. (Co-Advisor) for directing me and guiding me through difficulties and complete this research. From the beginning, they had confidence in my abilities to not only complete a degree but to complete it with excellence. I would like to thank Mr. Supanna Wirija (SMPK2 PENABUR Principal), Mr. Teguh Santoso (Teacher) and Mr. Christophorus Tommy Astanto (Teacher) for providing me access to Moodle usage and respondents, and advised me on research model.

\section{Appendix A: Questionnaire}

\begin{tabular}{|c|c|c|c|c|c|c|c|}
\hline Constructs & Question & Questions & 1 & 2 & 3 & 4 & 5 \\
\hline \multirow[t]{4}{*}{$\mathrm{PE}$} & PE1 & I find Moodle useful in my learning & & & & & \\
\hline & PE2 & Moodle helps me to understand topics better & & & & & \\
\hline & PE3 & Moodle makes me achieve more & & & & & \\
\hline & PE4 & Moodle makes me get higher scores/grades & & & & & \\
\hline \multirow[t]{6}{*}{$\mathrm{EE}$} & EE1 & I find that Moodle is easy to use & & & & & \\
\hline & EE2 & I can operate Moodle easily & & & & & \\
\hline & EE3 & $\begin{array}{l}\text { Teachers can organize materials and quizzes/ questions } \\
\text { bank easily }\end{array}$ & & & & & \\
\hline & EE4 & $\begin{array}{l}\text { Teachers can analyze Students weakness in certain topics } \\
\text { or subjects easily }\end{array}$ & & & & & \\
\hline & EE5 & $\begin{array}{l}\text { Students can self-prepare themselves before going into } \\
\text { classes easily }\end{array}$ & & & & & \\
\hline & EE6 & $\begin{array}{l}\text { Students can easily review materials or repeat subjects for } \\
\text { those they considered they are weak in }\end{array}$ & & & & & \\
\hline \multirow[t]{4}{*}{ SI } & SI1 & Students: My friends think I should use Moodle & & & & & \\
\hline & SI2 & My teachers think I should use Moodle & & & & & \\
\hline & SI3 & My IT teachers give their support in the use of Moodle & & & & & \\
\hline & SI4 & My school supported the use of Moodle & & & & & \\
\hline \multirow[t]{2}{*}{$\mathrm{CE}$} & CE1 & I'm an IT-minded Student & & & & & \\
\hline & CE2 & I'm an IT-minded Teacher & & & & & \\
\hline \multirow[t]{4}{*}{ PEJ } & PEJ1 & $\begin{array}{l}\text { Teachers enjoy organizing materials and quizzes/ } \\
\text { questions bank }\end{array}$ & & & & & \\
\hline & PEJ2 & $\begin{array}{l}\text { Teachers enjoy analyzing Students weakness in certain } \\
\text { topics or subjects }\end{array}$ & & & & & \\
\hline & PEJ3 & Students enjoy self-preparation before going into classes & & & & & \\
\hline & PEJ4 & $\begin{array}{l}\text { Students enjoy reviewing materials or repeating subjects } \\
\text { for those they considered they are weak in }\end{array}$ & & & & & \\
\hline \multirow[t]{6}{*}{ FC } & FC1 & I have hardware required to use Moodle & & & & & \\
\hline & FC2 & I have knowledge and skill to operate Moodle & & & & & \\
\hline & FC3 & $\begin{array}{l}\text { Moodle is compatible with other applications I use } \\
\text { (Microsoft Office) }\end{array}$ & & & & & \\
\hline & FC4 & $\begin{array}{l}\text { My school provided support team in case of difficulties I } \\
\text { experience with Moodle }\end{array}$ & & & & & \\
\hline & FC5 & Moodle enable Students to learn from home & & & & & \\
\hline & FC6 & $\begin{array}{l}\text { Internet and server hardware performance encourage } \\
\text { Students/Teachers to use Moodle }\end{array}$ & & & & & \\
\hline BI & BI1 & I intend to use Moodle in the next (n) days & & & & & \\
\hline
\end{tabular}




\begin{tabular}{l|l|l|l|l|l|l|l|}
\hline Constructs & Question & Questions & 1 & 2 & 3 & 4 & 5 \\
\hline & BI2 & I plan to use Moodle in the next (n) days & & & & & \\
\hline
\end{tabular}

Note. $\mathrm{PE}=$ performance expectancy, $\mathrm{EE}=$ effort expectancy, $\mathrm{SI}=$ social influence, $\mathrm{CE}=$ Computer SelfEfficacy, $\mathrm{PEJ}=$ Perceived Enjoyment, $\mathrm{FC}=$ facilitating conditions, $\mathrm{BI}=$ behaviour intention.

\section{References}

Franzoni, Ana Lidia, and Said Assar, 2009. Student Learning Styles Adaptation Method Based on Teaching Strategies and Electronic Media. [Online]

Available at: http://www-public.int-evry.fr/ assar/pdf/ETS_Franzoni-Assar.pdf

Marchewka, Jack T., and Liu Chang, 2007. An Application of the UTAUT Model for Understanding Student Perceptions Using Course Management Software. Communications of the IIMA, pp. 9394.

Venkatesh et al, 2003. User acceptance of information technology: Toward a unified view. MIS Quarterly, pp. 425-478. 